This article was published in Journal of Membrane Science, 459, 207-216, 2014

http://dx.doi.org/10.1016/j.memsci.2014.02.013

\title{
Preparation and characterization of carbon molecular sieve membranes based on resorcinol-formaldehyde resin
}

Sandra C. Rodrigues ${ }^{a}$, Roger Whitley ${ }^{b}$, Adélio Mendes ${ }^{a, n}$

a LEPABE - Faculdade de Engenharia, Universidade do Porto, Rua Dr. Roberto Frias, 4200-465 Porto, Portugal

b Air Products and Chemicals, Inc., Hamilton Blvd., Allentown, PA 18195-1501, USA

\begin{abstract}
Carbon molecular sieve membranes (CMSM) were prepared on $\alpha$-alumina supports by carbonization of a resorcinol-formaldehyde resin loaded with boehmite. Two series of carbon membranes produced at $500^{\circ} \mathrm{C}$ and $550^{\circ} \mathrm{C}$ carbonization end temperatures were prepared. The influence of the carbonization end temperature on the structure, morphology and performance of the membranes was examined by scanning electron microscopy, thermogravimetric analysis, $\mathrm{CO} 2$ adsorption and permeation to $\mathrm{N} 2, \mathrm{O} 2, \mathrm{He}, \mathrm{H} 2$ and $\mathrm{CO} 2$ at temperatures from $25{ }^{\circ} \mathrm{C}$ to $120{ }^{\circ} \mathrm{C}$. SEM photographs showed carbon membranes with a thin and very uniform layer and a thickness of ca. $3 \mu \mathrm{m}$. Carbon dioxide adsorption isotherms revealed that all the produced carbon membranes have a welldeveloped microporous structure. Nevertheless, the membranes carbonized at $550{ }^{\circ} \mathrm{C}$ have more ultramicropores and a narrower pore size distribution. The permselectivity of CMSM prepared at this temperature surpasses the Robeson upper bound for polymeric membranes, especially regarding ideal selectivities of pairs $\mathrm{O} 2 / \mathrm{N} 2$ (O2 permeation rate: $9.85 \times 10^{-10} \mathrm{~mol} \mathrm{~m}-2 \mathrm{~s}-1 \mathrm{~Pa}-1$ and ideal selectivity: $>11.5$ ), $\mathrm{H} 2 / \mathrm{N} 2\left(\mathrm{H} 2\right.$ permeation rate: $5.04 \times 10^{-8} \mathrm{~mol} \mathrm{~m}-2 \mathrm{~s}-1 \mathrm{~Pa}-1$ and ideal selectivity: $>586$ ) and $\mathrm{He} / \mathrm{N} 2$ (He permeation rate: $4.68 \times 10^{-}-8 \mathrm{~mol} \mathrm{~m}^{-2} \mathrm{~s}-1$ $\mathrm{Pa}-1$ and ideal selectivity: $>544)$.
\end{abstract}

\section{Introduction}

Carbon molecular sieve membranes have emerged as promising candidates for gas separation applications because of their attractive characteristics such as superior thermal resistance, chemical stability in corrosive environments, high permeabilities, as well as excellent selectivities compared to polymeric membranes 
[1-3]. Carbon membranes are prepared by carbonization of polymeric precursors under controlled inert atmosphere [4,5]; the polymeric precursor should withstand high temperature treatment without much shrinkage [6] and should have a high carbon yield [1]. After the carbonization step, CMSM present an amorphous nanoporous skeleton [6,7]; Fig. 1 shows an HR-TEM photo of a carbon molecular sieve membrane showing no ordered structural building units [8].

CMSM have a slit-like pore structure, which provides a unique combination of micropore $(0.7-2 \mathrm{~nm})$ and ultramicropore (less than $0.7 \mathrm{~nm}$ ) networks [9,10]. The larger pores are responsible for sorption and ultramicropores are accountable for the molecular sieving mechanism since they approach the molecular dimensions of diffusing gas molecules and consequently allow the passage of smaller species of a gas mixture and obstruct the larger ones [2,5]. The exceptional gas separation performance of CMSM is made possible due to the combination of this molecular sieving trans- port with a solution-diffusion mechanism [4,6,11].

Some parameters such as carbonization conditions (heating rate, end temperature, soaking time and gas atmosphere) and pre-/post- treatment conditions (thermostabilization, oxidation and chemical vapor deposition) determine the microstructure and gas permeance properties of the carbon molecular sieve membranes [12-15]. But above all, polymer precursor has a crucial function in determining the final structure of the carbon membranes since different polymer precursors carbonized in the same conditions lead to carbon membranes with different properties [2,16].

Research efforts have been focused on carbon molecular sieve membranes for gas separation obtained from the carbonization of various polymeric precursors such as polyimides [15-21], cellulose [22,23], polyacrylonitrile [24], poly(furfuryl alcohol) $[25,26]$ and phenolic resins $[4,8,27,28]$. Nevertheless, the search for ways to produce carbon membranes with excellent separation proper- ties and stability, without losing the economical processability of polymeric membranes, still presents a major challenge in this field.

Resorcinol-formaldehyde resin (Fig. 2) makes an excellent precursor material for the production of CMSM due to its considerable fixed-carbon yield, high inherent purity and low cost [29-32].

However, very few studies have been reported on the production of carbon molecular sieve membranes from resorcinol-formaldehyde resin. Tanaka et al. [33] prepared microporous carbon membranes on a porous $\alpha$-alumina support by a partial carbonization of a resorcinol-formaldehyde resin for pervaporation applications. Dong et al. [34] prepared microporous carbon membranes on $\alpha$ alumina supports carbonizing resorcinol-formaldehyde polymer precursor and quaternary ammonium compounds (tetramethylammonium bromide and tetrapropylammonium) for dehydration of water/ethanol and water/isopropanol mixtures by pervaporation. Yoshimune et al. [35] obtained highly mesoporous carbon membranes by carbonizing sol-gel derived mesoporous resorcinol- 
formaldehyde membranes.

In general, the methods described in the literature to obtain supported carbon membranes are complex and the coating- carbonization cycle must be repeated several times to achieve crack-free CMSM, which needs time and special care. Only a few researchers have reported the development of defect-free membranes by a single dipping-drying-carbonization step [1,4,8, 36-40]. The addition of boehmite particles with needle shape to the CMSM precursor recently proved to be effective for producing crack-free supported membranes in a single dipping-drying carbonization step. Boehmite $(\mathrm{y}-\mathrm{AlO}(\mathrm{OH}))$ is an aluminum oxide hydroxide, and it has been recently used by our research team to prepare carbon molecular sieve membranes [4,8]. During carbonization, boehmite nanoparticles dehydrate and $\mathrm{Al}_{2} \mathrm{O} 3$ nanowires are formed and homogeneously distributed in the carbon matrix. Teixeira et al. [8] prepared composite carbon membranes from a Resol phenolic resin loaded with boehmite nanoparticles in a single coating-drying-carbonization step. The composite carbon membranes obtained exhibited high permeability to $\mathrm{C} 3 \mathrm{H} 6$ and considerable $\mathrm{C} 3 \mathrm{H} 6 / \mathrm{C} 3 \mathrm{H} 8$ ideal selectivity, well above the state-of- the-art plot for polymeric membranes for this separation. $\mathrm{O}_{2} / \mathrm{N}_{2}, \mathrm{He} / \mathrm{N}_{2}$ and $\mathrm{CO}_{2} / \mathrm{N}_{2}$ ideal selectivities of 5, 34 and 30, respectively, were achieved. In this study, the boehmite nanoparticles' key role was identified: these needle-shaped particles control the poly- meric precursor rheology.

This work proposes the incorporation of low cost nanoparticles (boehmite) in a low cost resorcinol-formaldehyde resin to prepare composite carbon molecular sieve membranes in a single dipping- drying-carbonization step. Defect-free supported carbon mem- branes were prepared successfully and reproducibly at different carbonization end temperatures of $500{ }^{\circ} \mathrm{C}$ (CMSM 500) and $550{ }^{\circ} \mathrm{C}$ (CMSM 550). Dry films of the composite top layer were pre- pared, and morphological characterization of the material was performed by scanning electron microscopy (SEM) and thermo- gravimetric analysis (TGA). Pore size distributions were obtained from the adsorption equilibrium isotherms of carbon dioxide at $0{ }^{\circ} \mathrm{C}$. Permeation experiments were performed to assess the permeability toward N2, $\mathrm{O} 2, \mathrm{CO} 2, \mathrm{He}$ and $\mathrm{H} 2$ as well as the ideal selectivities for separations of industrial relevance.

\section{Experimental}

\subsection{Materials}

A resorcinol-formaldehyde resin, used as precursor, was pro- vided by Continental Portugal. N-methyl-2-pyrrolidone (NMP) was supplied by Acros 
Organics. Boehmite nanoparticles (10\% Boehmite solution, particle size 8-20 nm) were supplied by Kawaken Fine Chemicals Co. Ltd. The $\alpha$-alumina tubular supports were purchased from Inopor. Non-porous alumina tubes were bought from Omega Engineering Limited. The permanent gases were supplied by Air Liquide (99.999\% pure).

\subsection{Tubular ceramic supports preparation}

The ends of the porous $\mathrm{Al} 2 \mathrm{O} 3$ supports were attached to non- porous $\mathrm{Al}_{2} \mathrm{O} 3$ tubes and sealed with a glass sealant at $1150^{\circ} \mathrm{C}$. The supports have a mean pore size of $200 \mathrm{~nm}$ (located in the outer part of the tube), an external diameter of 10 $\mathrm{mm}$ and a length of $70 \mathrm{~mm}$. An effective length of approximately $50 \mathrm{~mm}$ was left for dip-coating.

\subsection{Preparation of carbon molecular sieve membranes}

Resorcinol-formaldehyde resin was diluted in NMP to prepare a $15 \mathrm{wt} \%$ resin solution with a viscosity of ca. $0.04 \mathrm{~Pa}$ s and a $\mathrm{pH}$ of 4.6. A composite coating solution of $14 \mathrm{wt} \%$ of resorcinol-formaldehyde resin, $0.5 \mathrm{wt} \%$ of boehmite nanoparticles, $0.6 \mathrm{wt} \%$ of ethylenediamine monohydrate and $85.6 \mathrm{wt} \%$ of NMP was prepared. Ethylenediamine monohydrate was used as a basic catalyst of the polymerization reaction.

Supported membranes were then prepared by dip coating the alumina tubular supports in the coating solution using a vacuum pump. The resorcinolformaldehyde resin-based membranes were dried in a rotating oven at $70{ }^{\circ} \mathrm{C}$ overnight to avoid a quick release of the solvent during the carbonization stage that could damage the carbon matrix, causing cracks or defects. Subsequently, the membranes were left at $90{ }^{\circ} \mathrm{C}$ for $7 \mathrm{~h}$.

The carbonization of the precursor was accomplished in a quartz tube (80 $\mathrm{mm}$ in diameter and $1.5 \mathrm{~m}$ in length) inside a tubular horizontal Termolab TH furnace. To guarantee temperature homogeneity along the quartz tube, the furnace has three separating heating elements controlled by three PID control heating parameters. Fig. 3 gives a schematic overview of the furnace.

The carbonization was performed under N2 atmosphere, flow rate of $170 \mathrm{~mL}$ $\min ^{-1}$ and a heating rate of $1^{\circ} \mathrm{C} \min -1$. Fig. 4 shows the temperature history to prepare the carbon molecular sieve membranes from resorcinolformaldehyde resin.

First, the temperature was raised from ambient to $110^{\circ} \mathrm{C}$ at a rate of $1^{\circ} \mathrm{C}$ min -1 and held at this temperature for $30 \mathrm{~min}$; subsequently, the temperature was increased from $110^{\circ} \mathrm{C}$ to the desired carbonization end temperature (again at a 
heating rate of $1^{\circ} \mathrm{C} \min ^{-1}$ ) and held at that temperature for $2 \mathrm{~h}$; afterward, the membranes were allowed to cool to room temperature.

2.4. Scanning electron microscopy and energy dispersive X-ray spectroscopy analysis

The samples were fixed onto aluminum sample holders with Araldite ${ }^{\mathrm{Tm}}$ cement, sputter-coated with palladium-gold (Bal-Tec - SCD 050) and observed in a scanning electron microscope (SEM, FEI Quanta 400FEG).

\subsection{Thermogravimetric analysis}

TGA were carried out in a Netzsch TG 209 F1 Iris thermogravi- metric balance with a resolution of $0.1 \mathrm{mg}$. It was analyzed the dipping solution used to prepare the CMSM. The sample was previously dried in the oven at $110{ }^{\circ} \mathrm{C}$ for $72 \mathrm{~h}$ in order to remove most of the solvent. The characteristic curve was determined from

$20{ }^{\circ} \mathrm{C}$ to $900{ }^{\circ} \mathrm{C}$ under $\mathrm{N}_{2}$ atmosphere with a heating rate of $10^{\circ} \mathrm{C}$ min -1 .

\subsection{Pore size characterization}

The pore size distribution and the porosity volume of the produced CMSM were obtained based on the adsorption equilibrium isotherm of $\mathrm{CO} 2$ at $0{ }^{\circ} \mathrm{C}$ determined in a magnetic suspension balance as described elsewhere [41].

\subsection{Permeation experiments}

The permeation properties of the produced CMSM were obtained by probing the membrane with pure gases. Briefly, N2, O2, He, $\mathrm{H}_{2}$ and $\mathrm{CO}_{2}$ were introduced shell side at 0.11-0.15 MPa feed pressure (Horiba Stec, model UR7340) and the permeated flow rate at room pressure was determined by one of the three flow meters (Bronkhorst, ranges: 0-1, 0-10 and 0-100 $\mathrm{mLN} \min -1$ ) [8].

All the results obtained are averages based on the measurements of at least three membrane samples prepared and tested under the same conditions.

\section{Results and discussion}

\subsection{Scanning electron microscopy and energy dispersive X-ray spectroscopy analysis}

The morphology and qualitative elemental composition of carbon molecular sieve membranes were determined by scanning electron microscopy and energy 
dispersive X-ray spectroscopy (EDS), respectively. SEM microphotographs of cross-section of a supported CMSM 550 are shown in Fig. 5.

Fig. 5(a) indicates that two different parts can be distinguished: the top thin layer and the porous alumina support. A defect-free carbon film of ca. $3 \mu \mathrm{m}$ thickness was uniformly formed on the top of the $\alpha$-alumina tubular support. Fig. 5(b) shows that $\mathrm{Al} 2 \mathrm{O} 3$ nanoparticles were well distributed in the carbon matrix. EDS analysis also revealed a uniform carbon and $\mathrm{Al}_{2} \mathrm{O} 3$ composition along the layer thickness (data not shown).

\subsection{Thermogravimetric analysis}

TGA was used to assess the thermal decomposition kinetics and stability of polymer in an inert atmosphere. TGA was performed on the dry dipping solution used for the preparation of the CMSM. The characteristic curve was obtained under N2 atmosphere and is plotted in Fig. 6.

Fig. 6 shows that from room temperature to $175^{\circ} \mathrm{C}$ the composite film loses about $2 \%$ of its original weight. This loss is attributed to the release of adsorbed water from the precursor. Between $175{ }^{\circ} \mathrm{C}$ and $350{ }^{\circ} \mathrm{C}$ the sample loses ca. $30 \%$ of its original weight, which should be related to the degradation of the resorcinol-formaldehyde resin. It has been reported that at this temperature gases from the amine decomposition generate micropores in the carbonized resorcinol-formaldehyde resin membrane [42]. Between $500{ }^{\circ} \mathrm{C}$ and $800{ }^{\circ} \mathrm{C}$ a lower weight loss of $15 \%$ is observed; at $900{ }^{\circ} \mathrm{C}$ the total weight loss is approximately $44 \%$; this weight loss is in accordance with the literature [35].

\subsection{Porosity assessment}

The adsorption of nitrogen at $-196^{\circ} \mathrm{C}$ is the most frequently used technique to assess the microporosity of carbonaceous materials. However, when ultramicroporosity is involved some diffusional limitations occur and adsorption of carbon dioxide at $0{ }^{\circ} \mathrm{C}$ is a good alternative to overcome this problem $[43,44]$. The adsorption equilibrium isotherms of $\mathrm{CO} 2$ at $0^{\circ} \mathrm{C}$ for $\mathrm{CMSM} 500$ and CMSM 550 are plotted in Fig. 7.

Dubinin-Raduschkevisch (DR) equation is commonly used to describe the adsorption in micropores:

$$
\frac{w}{w_{0}}=\exp \left[-\left(\frac{R T \ln \left(P_{0} / P\right)}{E_{0}}\right)^{2}\right]
$$


where $W$ is the micropore volume, $P$ is the pressure, $W_{0}$ is the total micropore volume, E0 is the characteristic energy for adsorption, $P 0$ is the vapor pressure of the free liquid, $R$ is the gas constant and $T$ is the absolute temperature. However, the DR equation only provides a reasonable description of adsorption in micropores when the characteristic curve obtained from CO2 adsorption is linear. Recently a more general equation was proposed, the Dubinin- Astakhov（DA）equation:

$$
\frac{w}{w_{0}}=\exp \left[-\left(\frac{R T \ln \left(P_{0} / P\right)}{E_{0}}\right)^{n}\right]
$$

where $n$ is an adjustable parameter. DR equation results from DA equation for the particular case of $n=2$.

In the present work, the characteristic curves obtained from the $\mathrm{CO}_{2}$ adsorption isotherm on CMSM 500 and CMSM 550 are not very linear, indicating that the DR equation could not provide reasonable descriptions. Therefore, micropore volume and the characteristic energy for adsorption were determined by fitting the DubininAstakhov equation to experimental data. Fig. 8 presents the characteristic curve for CMSM 550.

It can be seen that the DA equation with $n$ 2:6 fits very well the experimental data. It is important to note that the slope of the plot is related to E0 and the intercept is related to $W_{0}$. Table 1 presents a summary of the structural parameters for the studied samples. Generally, empiric correlations developed by Stoeckli are used to estimate the mean pore width. However, Stoeckli equation can only be used when the DR equation applies. For that reason, the mean pore width in the present work was determined by a weighted average. For CMSM 550 , the micropore volume of $0.40 \mathrm{~cm}^{3} \mathrm{~g}-1$ is slightly higher when compared with other reported values $[4,21,41,45,46]$. However, the mean pore width (obtained by a weighted average) has the usual value found for carbon molecular sieves $[4,45,46]$. For CMSM 500, the mean pore width (obtained by a weighted average) is a little higher when compared with other values in the literature $[4,8,45,46]$.

Pore size distribution for all carbon molecular sieve membranes was obtained using the method proposed by Do et al. [43,47] for the determination of micropore size distribution in carbonaceous materials. Figs. 9 and 10 show the pore size distribution obtained for CMSM 550 and CMSM 500, respectively.

It can be seen that the studied carbon membranes present ultramicropores (0.3-0.7 $\mathrm{nm}$ range) and larger micropores (0.7-1 nm). However, CMSM 500 have a large number of micropores with larger dimensions when compared to CMSM 
550. On the other hand, CMSM 550 have a large number of micropores with narrower pore size distributions.

These small changes in the number and size of both ultra- micropores and larger micropores influence the permeability and permselectivity performance of both membranes, as will be shown in Section 3.4.

\subsection{Single gas permeation experiments}

The permeance of the supported CMSM obtained at $500{ }^{\circ} \mathrm{C}$ and $550{ }^{\circ} \mathrm{C}$ was assessed for $\mathrm{N}_{2}(0.364 \mathrm{~nm}), \mathrm{O}_{2}(0.346 \mathrm{~nm}), \mathrm{He}(0.260 \mathrm{~nm}), \mathrm{H}_{2}(0.290 \mathrm{~nm})$ and $\mathrm{CO} 2(0.335 \mathrm{~nm})$ - the values in brackets correspond to the kinetic diameter of the gases [48].

The produced CMSM were exposed to the room conditions for 6 days. Afterward, the samples were heated at various temperatures $\left(140^{\circ} \mathrm{C}, 160^{\circ} \mathrm{C}\right.$ and $200^{\circ} \mathrm{C}$ ) for $2 \mathrm{~h}$ under $\mathrm{N}_{2}$ atmosphere with a heating rate of $0.7^{\circ} \mathrm{C} \min -1$. The feed pressure was varied between 0.11 $\mathrm{MPa}$ and $0.15 \mathrm{MPa}$ while the permeate was kept at ca. $0.10 \mathrm{MPa}$ (atmospheric pressure). Gas permeation experiments were carried out at $25-120^{\circ} \mathrm{C}$.

The effect of carbonization end temperature on the permeability of two sets of resorcinol-formaldehyde carbon membranes is summarized in Fig. 11.

It can be concluded that the devised preparation process originates membranes with very similar permeation properties. Moreover, the samples carbonized at higher end temperature (CMSM 550) have generically smaller gas permeation rate; for example, the permeability to $\mathrm{N}_{2}$ became around 3 times smaller when compared to CMSM 500 samples. This can be attributed to the ultramicropores shrinkage [49,50]. CMSM 500 also have a larger mean pore width, $\ell^{1 / 4} 0.68 \mathrm{~nm}$ compared to CMSM 550, $\ell^{1 / 4} 0.58 \mathrm{~nm}$ (Table 1). However, CMSM 550 actually have a larger volume of ultramicropores (comparing Figs. 9 and 10), which gives He a higher permeance in CMSM 550 than in CMSM 500.

The performance of a membrane toward a separation is characterized by the permeability to the target species as well as the corresponding selectivities. Under all tested conditions, it was observed that the best compromise between permeability and selectivity was achieved for the membranes carbonized at $550{ }^{\circ} \mathrm{C}$, activated at $140{ }^{\circ} \mathrm{C}$ and measured at $120^{\circ} \mathrm{C}$. Therefore, these results will be further discussed here.

Fig. 12, Table 2 and Fig. 13, Table 3 show the permeances as a function of the feed pressure for CMSM 500 and CMSM 550, respectively.

The permeance toward all gases is pressure-dependent: Nishiyama et al. [42] and Lagorsse et al. [45] reported that this behavior seems to become more evident as the intensity of the adsorbate/adsorbent interactions increases. Since $\mathrm{CO}_{2}$ shows a 
more pronounced permeance increase with pressure, $\mathrm{CO} 2$ should have more affinity to the resorcinol-formaldehyde based carbon membranes than the other gases.

The effect of temperature on the permeance of CMSM 550 to the probing gases is illustrated in Fig. 14.

It can be seen that membrane permeance increases as the temperature increases. This reveals that the gas transport through the carbon molecular sieve membranes is an activated diffusion process, as expected for a molecular sieve mechanism [2]. From the change of CMSM permeance with temperature, the apparent activation energy can be estimated according to the following Arrhenius equation:

$$
\ln (P)=-\frac{E_{a}}{R T}+\ln \left(\frac{D_{0}}{R T}\right)
$$

where $D 0$ is a pre-exponential factor, $E a$ is the apparent activation energy, $P$ is the permeability, $R$ is the gas constant and $T$ is the absolute temperature.

The estimated apparent activation energies for $\mathrm{O}_{2}, \mathrm{He}, \mathrm{H}_{2}$ and $\mathrm{CO}_{2}$ are 17, 7, 10.8 and $18.2 \mathrm{~kJ} / \mathrm{mol}$, respectively. These values are relatively close to other values reported in literature [51]. The apparent activation energy for N2 was not calculated because permeation data are just available for temperatures of $100^{\circ} \mathrm{C}$ and above (see Fig. 14), and therefore there were not enough data to make the corresponding Arrhenius plot.

Ideal selectivities obtained for both carbon molecular sieve membrane sets are shown in Table 4.

It can be seen that ideal selectivity for all gas pairs increases significantly when the membrane carbonization end temperature increases from $500{ }^{\circ} \mathrm{C}$ to $550{ }^{\circ} \mathrm{C}$. Small differences observed in pore size distribution and mean pore width are very important and strongly influence the diffusion of molecules with closer sizes such as $\mathrm{N}_{2}, \mathrm{O}_{2}$ and $\mathrm{CO}_{2}$.

The obtained permeabilities and ideal selectivities were inserted into the semi-empirical plots devised by Robeson in 2008 [52]. The permeability is expressed in Barrer, which equals to $3.35 \times 10^{-16} \mathrm{~mol} \mathrm{~m} \mathrm{~m}-2 \mathrm{~s}^{-1} \mathrm{~Pa}^{-1}$. Figs. 15-18 illustrate the upper bound limits for $\mathrm{O}_{2} / \mathrm{N}_{2}, \mathrm{He}_{\mathrm{N}}, \mathrm{H}_{2} / \mathrm{N}_{2}$ and $\mathrm{CO}_{2} / \mathrm{N}_{2}$, respectively.

CMSM 550 showed promising results for the separation of $\mathrm{O}_{2} / \mathrm{N}_{2}$ (permeability: 8.7 Barrer; and ideal selectivity: 411.5), H2/N2 (permeability: 445.6 Barrer; and ideal selectivity: 4586) and He/N2 (permeability: 413.8 Barrer; and ideal selectivity: 4544). Finally, Fig. 19 compares these results with permeation data of CMSM produced from other low cost precursors (phenolformaldehyde resins).

It can be concluded that CMSM 550 exhibit higher ideal selectivities toward 
$\mathrm{O} 2 / \mathrm{N}_{2}, \mathrm{He} / \mathrm{N}_{2}$ and $\mathrm{H}_{2} / \mathrm{N}_{2}$ and higher permeabilities toward $\mathrm{H}_{2}$ and $\mathrm{He}$ when compared to similar studies $[1,4,8,36,37,53-57]$. However, lower permeabilities were obtained toward $\mathrm{O} 2[36,53,54,56]$

\section{Conclusions}

Carbon molecular sieve membranes were successfully prepared in a single dipping-drying-carbonization sequence. Membranes with reproducible properties were prepared from resorcinol- formaldehyde resin, a low cost precursor, loaded with boehmite nanoparticles. The effect of the carbonization end temperature was assessed and better separation properties were found for sample CMSM 550, carbonized in an inert atmosphere at $550{ }^{\circ} \mathrm{C}$. For improving their permeation stability, membranes were contacted with ambient air for 6 days and activated at $140^{\circ} \mathrm{C}$ under N2 atmosphere. Carbon molecular sieve membranes carbonized at $550{ }^{\circ} \mathrm{C}$ end temperature showed a large number of micropores with a narrower pore-size distribution and much higher ideal selectivities and relatively similar gas permeation rates than those produced at $500{ }^{\circ} \mathrm{C}$.

The Robeson upper bound for polymeric membranes was overtaken by CMSM 550 , regarding $\mathrm{O} 2 / \mathrm{N} 2\left(\mathrm{O} 2\right.$ permeation rate: $9.85 \times 10^{-10} \mathrm{~mol} \mathrm{~m}^{-2} \mathrm{~s}^{-1} \mathrm{~Pa}^{-}$ 1 and ideal selectivity: $>11.5), \mathrm{H}_{2} / \mathrm{N}_{2}$ ( $\mathrm{H}_{2}$ permeation rate: $5.04 \times 10^{-8} \mathrm{~mol} \mathrm{~m}-2 \mathrm{~s}^{-1} \mathrm{~Pa}^{-1}$ and ideal selectivity: >586) and $\mathrm{He} / \mathrm{N}_{2}$ (He permeation rate: $4.68 \times 10^{-8} \mathrm{~mol} \mathrm{~m}^{-2} \mathrm{~s}^{-1} \mathrm{~Pa}-1$ and ideal selectivity: >544) separations. CMSM 550 are superior to many reported carbon membranes produced from other low cost precursors, indicating that CMSM produced from resorcinol-formaldehyde resin have potential for gas separation.

\section{Acknowledgments}

The authors would like to acknowledge the funding provided by the Portuguese Foundation for Science and Technology (FCT) through the Projects PTDC/EQUEQU/114944/2009 and PTDC/EQU- EQU/104217/2008. The authors are also grateful to the European Union's Seventh Framework Programme (FP7/2007) for Fuel Cells and Hydrogen Joint Technology for funding under Grant agreement number 303476. The authors are thankful to CEMUP for the SEM/EDS analysis. 


\section{References}

1 W. Wei, G. Qin, H. Hu, L. You, G. Chen, Preparation of supported carbon molecular sieve membrane from novolac phenol-formaldehyde resin, J. Membr. Sci. 303 (2007) 80-85.

2 A.F. Ismail, L.I.B. David, A review on the latest development of carbon membranes for gas separation, J. Membr. Sci. 193 (2003) 1-18.

3 P.S. Tin, T.S. Chung, S. Kawi, M.D. Guiver, Novel approaches to fabricate carbon molecular sieve membranes based on chemical modified and solvent treated polyimides, Microporous Mesoporous Mater. 73 (2004) 151-160.

4 M. Teixeira, M. Campo, D.A. Tanaka, M.A. Tanco, C. Magen, A. Mendes, Carbon $\mathrm{Al} 2 \mathrm{O} 3 \mathrm{Ag}$ composite molecular sieve membranes for gas separation, Chem. Eng. Res. Des. 90 (2012) 2338-2345.

5 A.B. Fuertes, T.A. Centeno, Preparation of supported carbon molecular sieve membranes, Carbon 37 (1999) 679-684.

6 Y.H. Sim, H. Wang, F.Y. Li, M.L. Chua, T.S. Chung, M. Toriida, S. Tamai, High performance carbon molecular sieve membranes derived from hyperbranched polyimide preursors for improved gas separation applications, Carbon 53 (2013) 101-111.

7 M. Kiyono, P.J. Williams, W.J. Koros, Effect of pyrolysis atmosphere on separation performance of carbon molecular sieve membranes, J. Membr. Sci. 350 (2010) 2-10.

8 M. Teixeira, M.C. Campo, D.A. Tanaka, M.A. Tanco, C. Magen, A. Mendes, Composite phenolic resin-based carbon molecular sieve membranes for gas separation, Carbon 49 (2011) 4348-4358.

9 S. Lowell, J.E. Shields, M.A. Thomas, M. Thommes, Characterization of Porous Solids and Powders: Surface Area, Pore Size and Density, Kluwer Academic Publishers, The Netherlands (2004) 26 (Chapter 4).

10 A.J. Burggraaf, L. Cot, Fundamentals of Inorganic Membrane Technology, Elsevier Science, The Netherlands (1996) 71 (Chapter 4).

11 M.B. Rao, S. Sircar, Nanoporous carbon membranes for separation of gas mixtures by selective surface, J. Membr. Sci. 85 (1993) 253-264.

12 C.W. Jones, W.J. Koros, Carbon molecular sieve gas separation membranes I. Preparation and characterization based on polyimide precursors, Carbon 32 (1994) 1419-1425.

13 M. Yoshino, S. Nakamura, H. Kita, K. Okamoto, N. Tanihara, Y. Kusuki, Olefin/ paraffin separation performance of carbonized membranes derived from an asymmetric hollow fiber membrane of 6FDA/BPDA-DDBT copolyimide, J. Membr. Sci. 215 (2003) 169-183.

14 H. Suda, K. Haraya, Alkene/alkane permselectivities of a carbon 
molecular sieve membrane, Chem. Commun. (1997) 93-94.

15 Y.K. Kim, H.B. Park, Y.M. Lee, Gas separation properties of carbon molecular sieve membranes derived from polyimide/polyvinylpyrrolidone blends: effect of the molecular weight of polyvinylpyrrolidone, J. Membr. Sci. 251 (2005) 159-167.

16 H.B. Park, Y.K. Kim, J.M. Lee, S.Y. Lee, Y.M. Lee, Relationship between chemical structure of aromatic polyimides and gas permeation properties of their carbon molecular sieve membranes, J. Membr. Sci. 229 (2004) 117-127.

17 Y.K. Kim, H.B. Park, Y.M. Lee, Carbon molecular sieve membranes derived from thermally labile polymer containing blend polymer and their gas separation properties, J. Membr. Sci. 243 (2004) 9-17.

18 Y.K. Kim, H.B. Park, Y.M. Lee, Preparation and characterization of carbon molecular sieve membranes derived from BTDA-ODA polyimide and their gas separation properties, J. Membr. Sci. 255 (2005) 265-273.

19 A.B. Fuertes, D.M. Nevskaia, T.A. Centeno, Carbon composite membranes from Matrimid $\mathbf{S}$ and Kapton $\mathbf{S}$ polyimides for gas separation, Microporous Meso- porous Mater. 33 (1999) 115-125.

20 K.M. Steel, W.J. Koros, An investigation of the effects of pyrolysis parameters on gas separation properties of carbon materials, Carbon 43 (2005) 1843-1856.

21 P.S. Tin, T.S. Chung, S. Kawi, M.D. Guiver, Novel approaches to fabricate carbon molecular sieve membranes based on chemical modified and solvent treated polyimides, Microporous Mesoporous Mater. 73 (2004) 151-160.

22 J.A. Lie, M.B. Hagg, Carbon membranes from cellulose: synthesis, performance and regeneration, J. Membr. Sci. 284 (2006) 79-86.

23 M. Campo, F.D. Magalhaes, A. Mendes, Carbon molecular sieve membranes from cellophane paper, J. Membr. Sci. 350 (2010) 180-188.

24 L.B. David, A.F. Ismail, Influence of the thermastablization process and soak time during pyrolysis process on the polyacrylonitrile carbon membranes for O2/N2 separation, J. Membr. Sci. 213 (2003) 285-291.

25 Y.D. Cheng, R.T. Yang, Preparation of carbon molecular sieve membranes and diffusion of binary mixtures in the membrane, Ind. Eng. Chem. Res. 33 (1994) 3146-3153.

26 C. Song, T. Wang, X. Wang, J. Qiu, Y. Cao, Preparation and gas separation properties of poly(furfuryl alcohol)-based C/CMS composite membranes, Sep. Purif. Technol. 58 (2008) 412-418.

27 A.B. Fuertes, I. Menendez, Separation of hydrocarbon gas mixtures using phenolic resin-based carbon membranes, Sep. Purif. Technol. 28 (2002) 29-41. 
28 F.K. Katsaros, T.A. Steriotis, A.K. Stubos, A. Mitropoulos, N.K. Kanellopoulos, S. Tennison, High pressure gas permeability of microporous carbon membranes, Microporous Mesoporous Mater. 8 (1997) 171-176.

29 S.J. Park, W.Y. Jung, Preparation and structural characterization of activated carbons based on polymeric resin, J. Colloid Interface Sci. 250 (2002) 196-200.

30 J. Hayashi, M. Uchibayashi, T. Horikawa, K. Muroyama, V. Gomes, Synthesizing activated carbons from resins by chemical activation with K2CO3, Carbon 40 (2002) 2727-2752.

31 S. Tenison, Phenolic-resin-derived activated carbons, Appl. Catal. A 173 (1998) 289-311.

32 T. Yamamoto, T. Sugimoto, T. Suzuki, S. Mukai, H. Tamon, Preparation and characterization of carbon cryogel microspheres, Carbon 40 (2002) 13451351.

33 S. Tanaka, T. Yasuda, Y. Katayama, Y. Miyake, Pervaporation dehydration performance of microporous carbon membranes prepared from resorcinol/ formaldehyde polymer, J. Membr. Sci. 379 (2012) 52-54.

34 Y.R. Dong, M. Nakao, N. Nishiyama, Y. Egashira, K. Ueyama, Gas permeation and pervaporation of water/alcohols through the microporous carbon mem- branes prepared from resorcinol/formaldehyde/quaternary ammonium compounds, Sep. Purif. Technol. 73 (2010) 2-7.

35 M. Yoshimune, T. Yamamoto, M. Nakaiwa, K. Haraya, Preparation of highly mesoporous carbon membranes via a sol-gel process using resorcinol and formaldehyde, Carbon 46 (2008) 1031-1036.

36 T.A. Centeno, A.B. Fuertes, Carbon molecular sieve membranes derived from a phenolic resin supported on porous ceramic tubes, Sep. Purif. Technol. 25 (2001) 379-384.

37 A.B. Fuertes, I. Menendez, Separation of hydrocarbons gas mixtures using phenolic resin-based carbon membranes, Sep. Purif. Technol. 28 (2002) 29-41.

38 A.B. Fuertes, Effect of air oxidation on gas separation properties of adsorption- selective carbon membranes, Carbon 39 (2001) 697-706.

39 A.B. Fuertes, Adsorption-selective carbon membrane for gas separation, J. Membr. Sci. 177 (2000) 9-16.

40 Menendez, A.B. Fuertes, Aging of carbon membranes under different environments, Carbon 39 (2001) 733-740.

41 M.C. Campo, F.D. Magalhaes, A. Mendes, Comparative study between a CMS membrane and a CMS adsorbent: Part I - morphology, adsorption equilibrium and kinetics, J. Membr. Sci. 346 (2010) 15-25.

42 N. Nishiyama, Y.R. Dong, T. Zheng, Y. Egashira, K. Ueyama, Tertiary amine- mediated synthesis of microporous carbon membranes, J. Membr. 
Sci. 280 (2006) 603-609.

43 C. Nguyen, D.D. Do, Adsorption of supercritical gases in porous media: determination of micropore size distribution, J. Phys. Chem. 103 (1999) 6900-6908.

44 S.W. Rutherford, C. Nguyen, J.E. Coons, D.D. Do, Characterization of carbon molecular sieves using methane and carbon dioxide as adsorptive probes, Langmuir 19 (2003) 8335-8342.

45 S. Lagorsse, F.D. Magalhães, A. Mendes, Carbon molecular sieve membranes - sorption, kinetic and structural characterization, J. Membr. Sci. 241 (2004) 275-287.

46 D. Cazorla-Amarós, J. Alcaniz-Monge, M.A. Casa-Lillo, A. Linares-Solano, $\mathrm{CO} 2$ as an adsorptive to characterize carbon molecular sieves and activated carbons, Langmuir 14 (1998) 4589-4596.

47 C. Nguyen, D.D. Do, K. Haraya, K. Wang, The structural characterization of carbon molecular sieve membrane (CMSM) via gas adsorption, J. Membr. Sci. 220 (2003) 177-182.

48 D.W. Breck, Zeolite Molecular Sieves, Structure, Chemistry and Use, JohnWiley \& Sons, New York, 1974.

49 T.H. Ko, W.S. Kuo, Y.H. Chang, Raman study of the microstructure changes of phenolic resin during pyrolysis, Polym. Compos. 21 (2000) $745-750$.

50 T.A. Centeno, J.L. Vilas, A.B. Fuertes, Effects of phenolic resin pyrolysis conditions on carbon membrane performance for gas separation, J. Membr. Sci. 228 (2004) 45-54.

51 A.F. Ismail, D. Rana, T. Matsuura, H.C. Foley, Carbon-Based Membranes for Separation Processes, Springer, New York (2011) 299-313.

52 L.M. Robeson, The upper bound revisited, J. Membr. Sci. 320 (2008) 390400.

53 Menendez, A.B. Fuertes, Aging of carbon membranes under different environments, Carbon 39 (2001) 733-740.

54 W. Zhou, M. Yoshino, H. Kita, K. Okamoto, Preparation and gas permeation properties of carbon molecular sieve membranes based on sulfonated phenolic resin, J. Membr. Sci. 217 (2003) 55-67.

$55 \mathrm{~W}$. Wei, H. Hu, L. You, G. Chen, Preparation of carbon molecular sieve membrane from phenol-formaldehyde novolac resin, Carbon 40 (2002) 465467.

56 A.B. Fuertes, Effect of air oxidation on gas separation properties of adsorptive- selective carbon membranes, Carbon 39 (2001) 697-706.

57 W. Shusen, Z. Meiyun, W. Zhizhong, Asymmetric molecular sieve carbon membranes, J. Membr. Sci. 109 (1996) 267-270. 


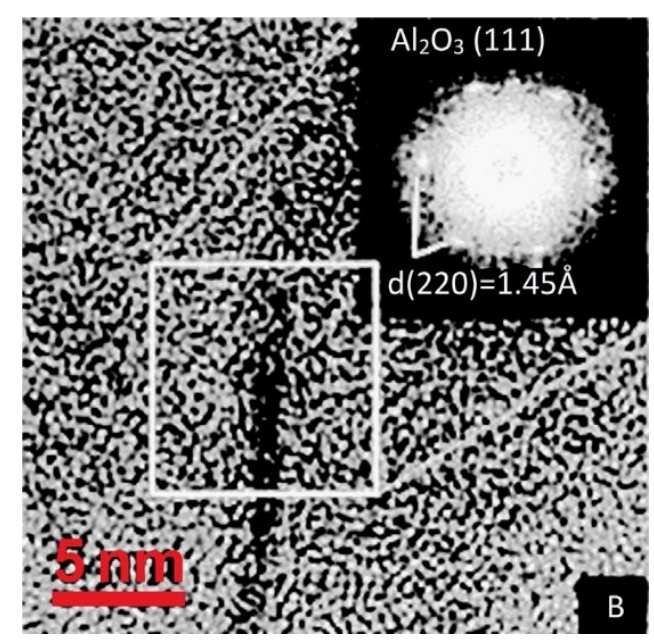

Fig. 1. HRTEM image of a composite carbon molecular sieve membrane derived from phenolic resin incorporated with ceramic particles of boehmite (carbonized at 550 oC) [24]

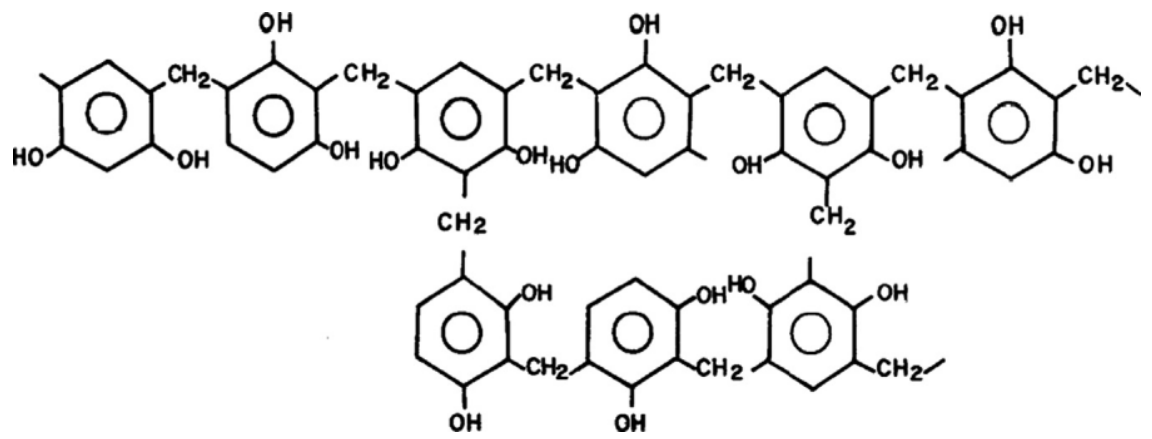

Fig. 2. Structure of a resorcinol-formaldehyde resin.

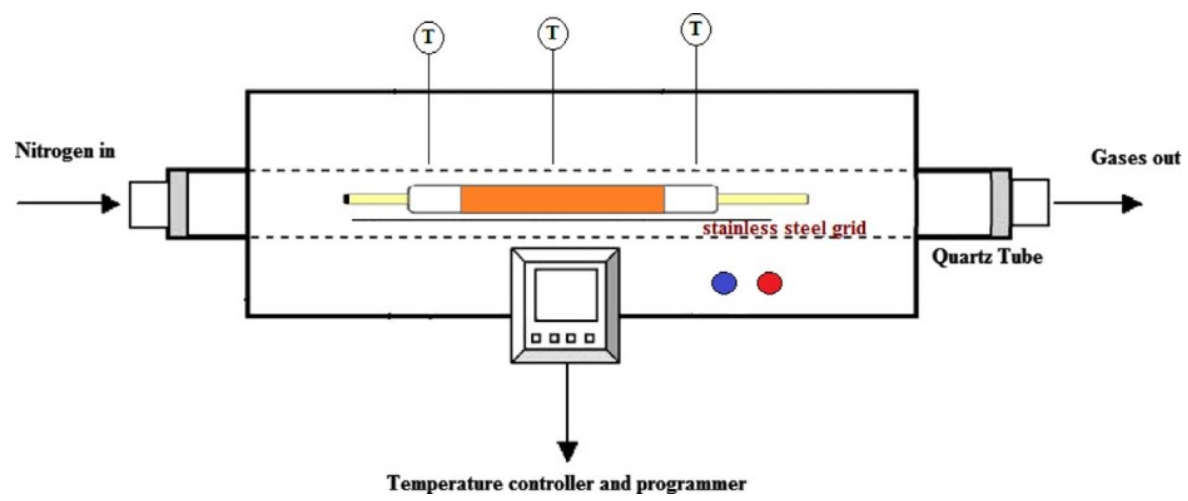

Fig. 3. Schematic overview of the furnace setup. 


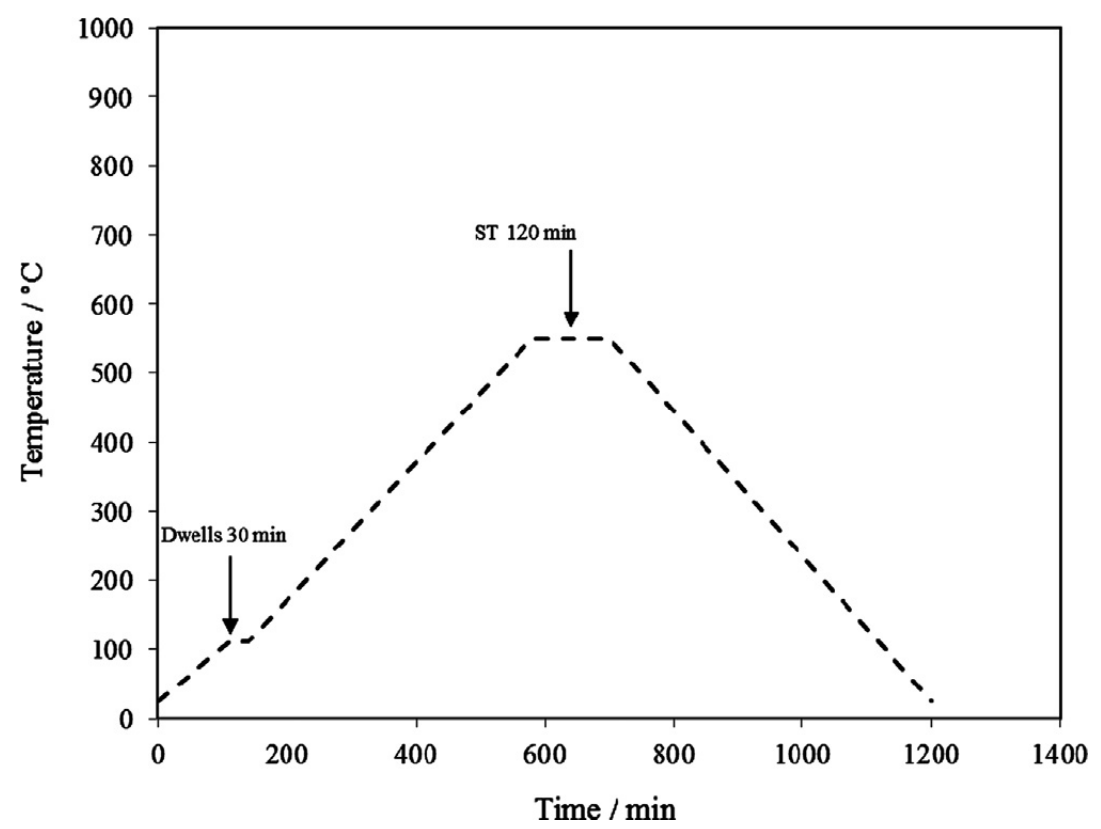

Fig. 4. Temperature history to prepare carbon molecular sieve membranes from resorcinol-formaldehyde resin. End temperature: $550^{\circ} \mathrm{C}$.

a

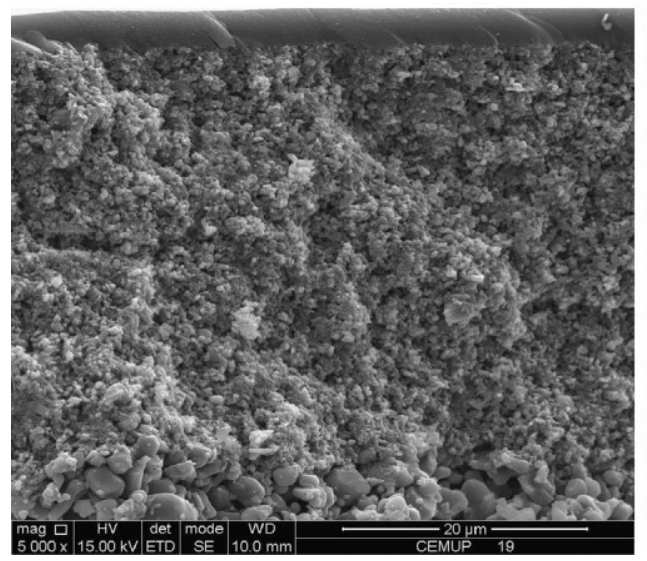

b

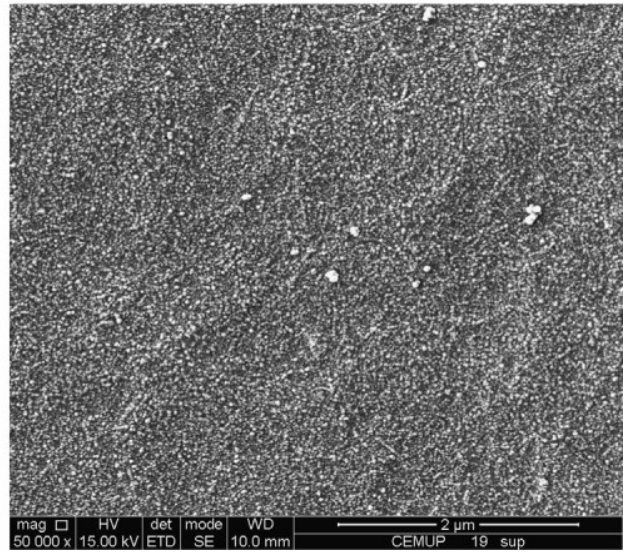

Fig. 5. SEM photographs of one-coated resorcinol-formaldehyde based carbon membrane carbonized at $550{ }^{\circ} \mathrm{C}$ : (a) cross section; (b) surface view. 


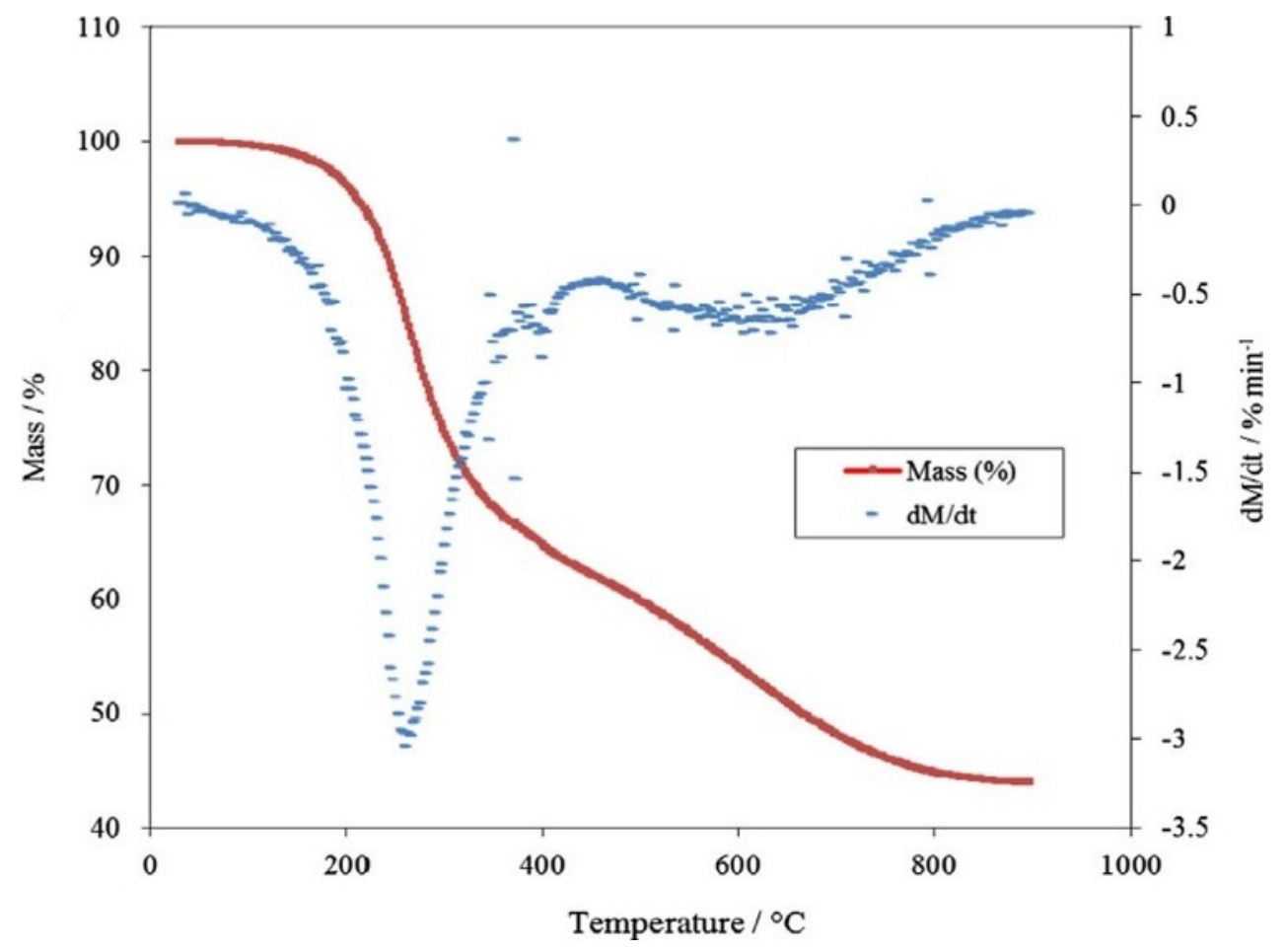

Fig. 6. Thermogravimetric analysis of composite dipping solution containing $14 \mathrm{wt} \%$ of resin and $0.5 \mathrm{wt} \%$ boehmite nanoparticles used to prepare CMSM

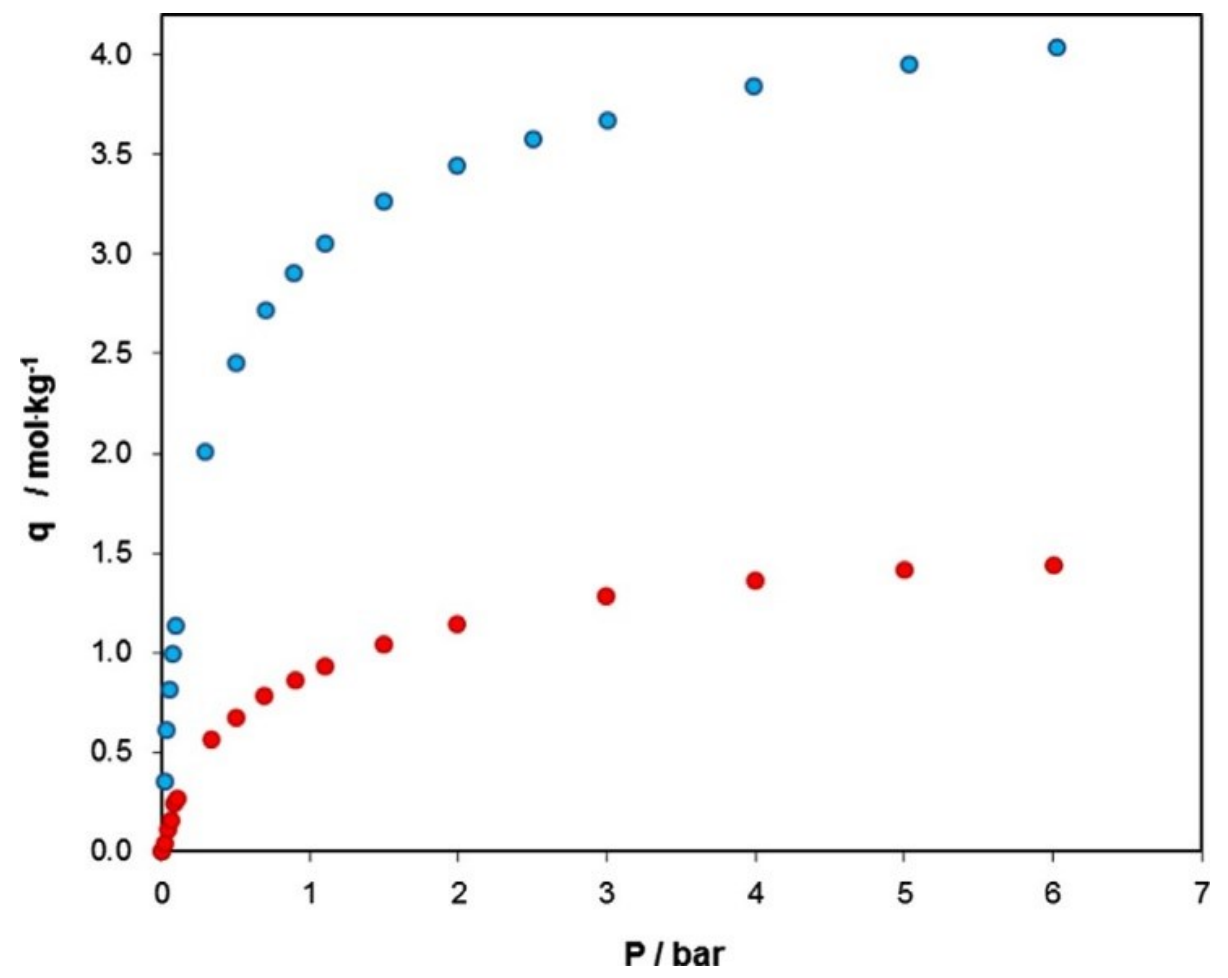

Fig. 7. Adsorption equilibrium isotherm of $\mathrm{CO} 2$ at 0 ㅇ for $\mathrm{CMSM} 500$ and CMSM 550. 


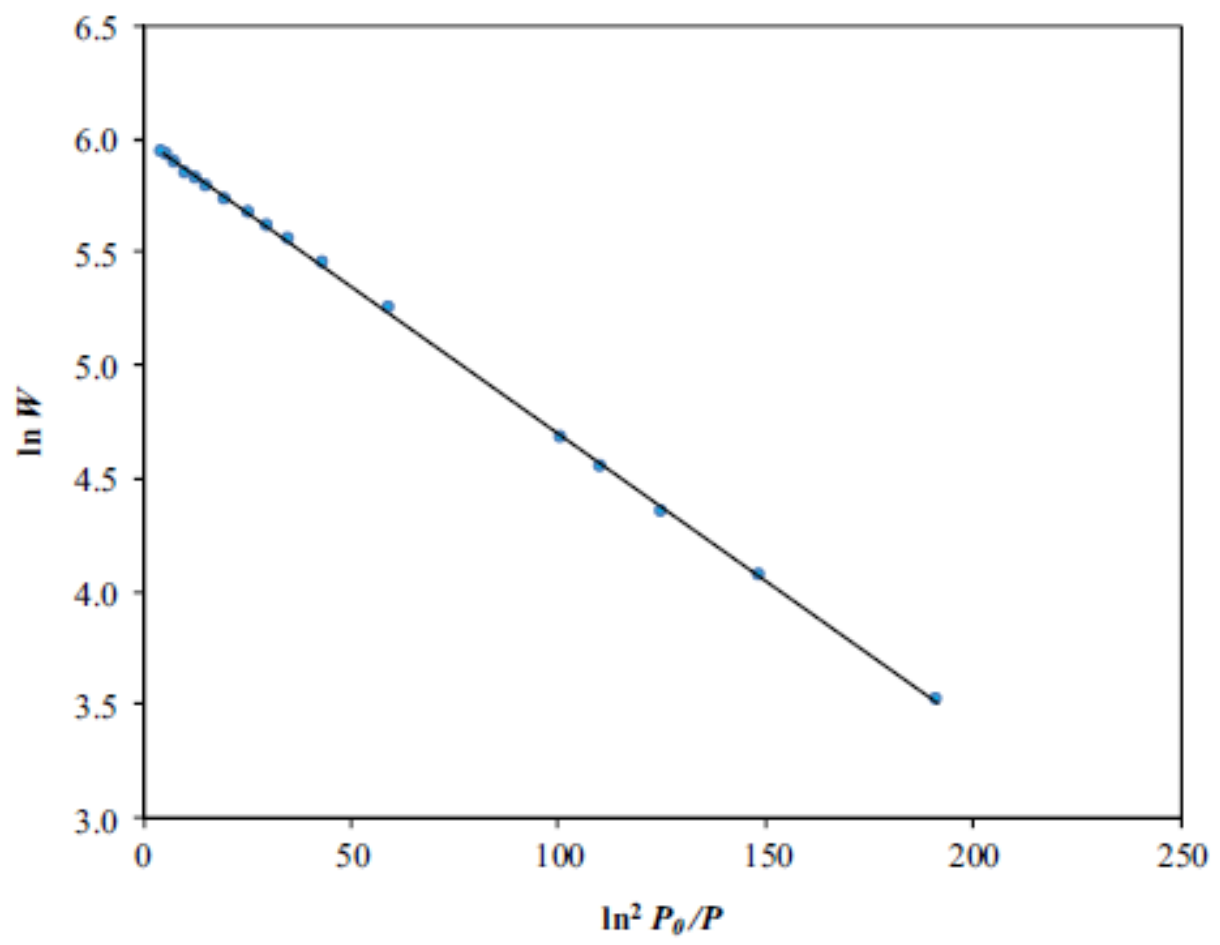

Fig. 8. $\mathrm{CO} 2$ characteristic curve for $\mathrm{CMSM} 550$ at $0{ }^{\circ} \mathrm{C}$ (points experimental data; solid line DA fitting).

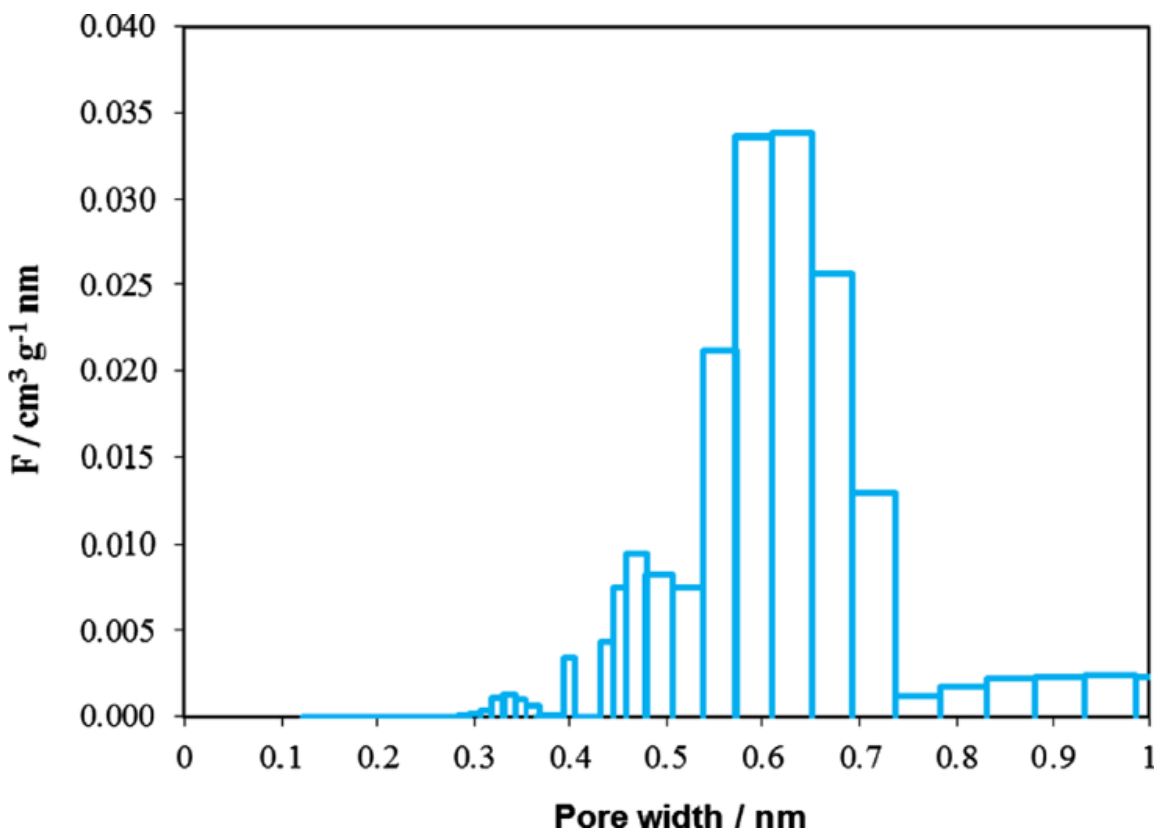

Fig. 9. Micropore size distribution for CMSM 550. 


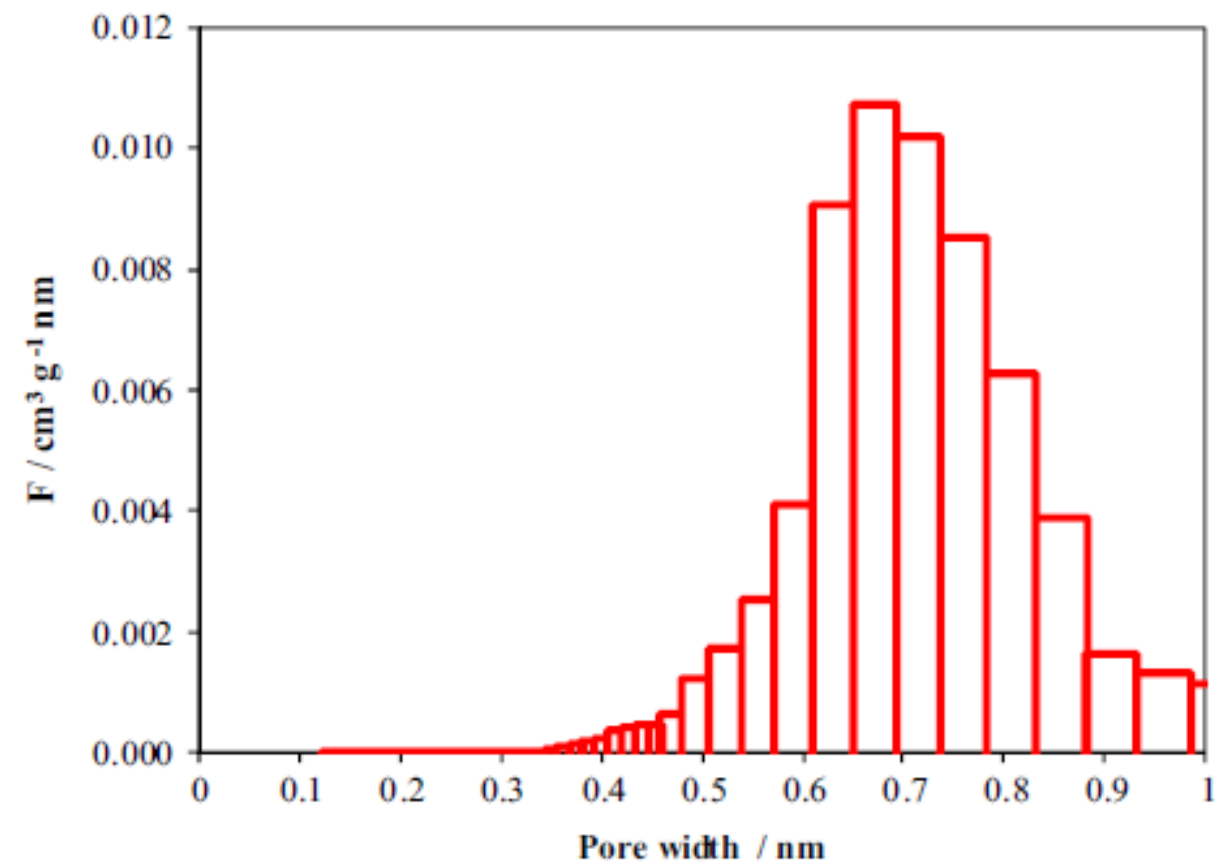

Fig. 10. Micropore size distribution for CMSM 500.

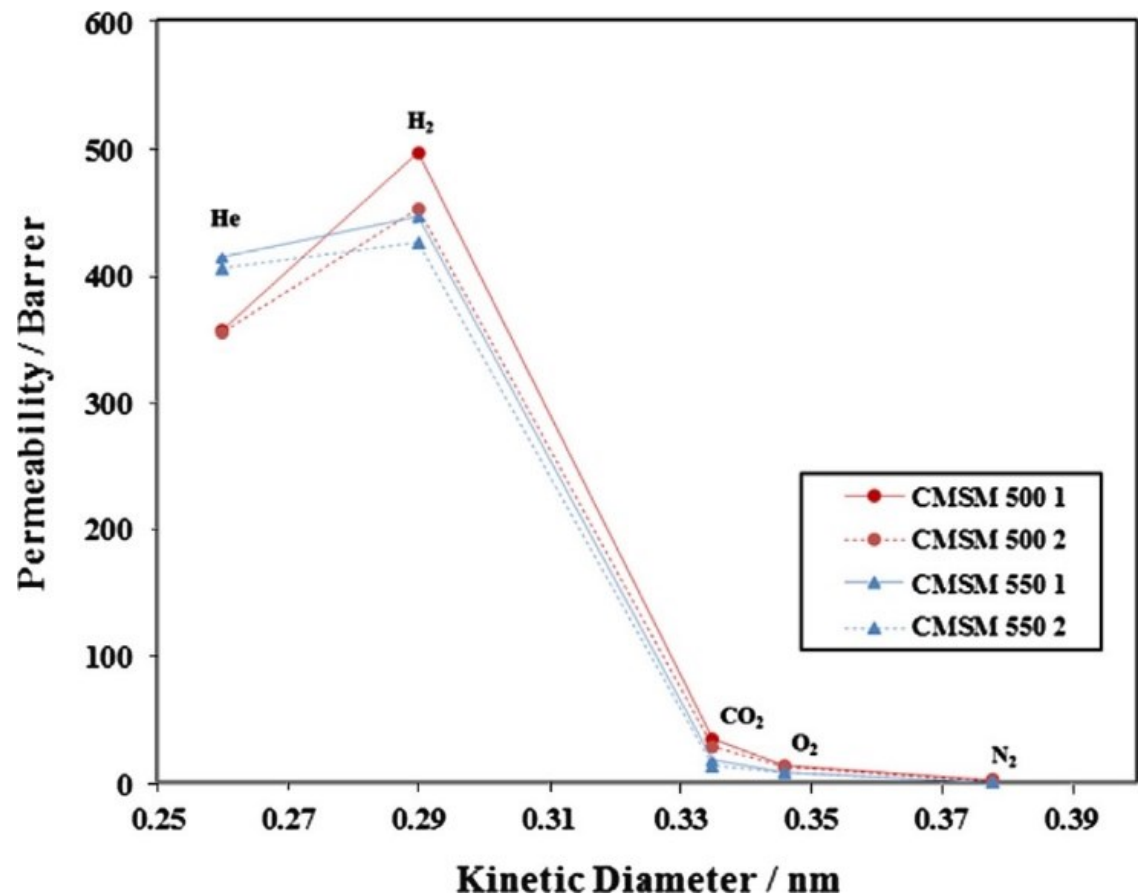

Fig. 11. Permeability as a function of kinetic diameter of gas molecules for two sets of supported carbon membranes obtained at different end carbonization temperatures. 


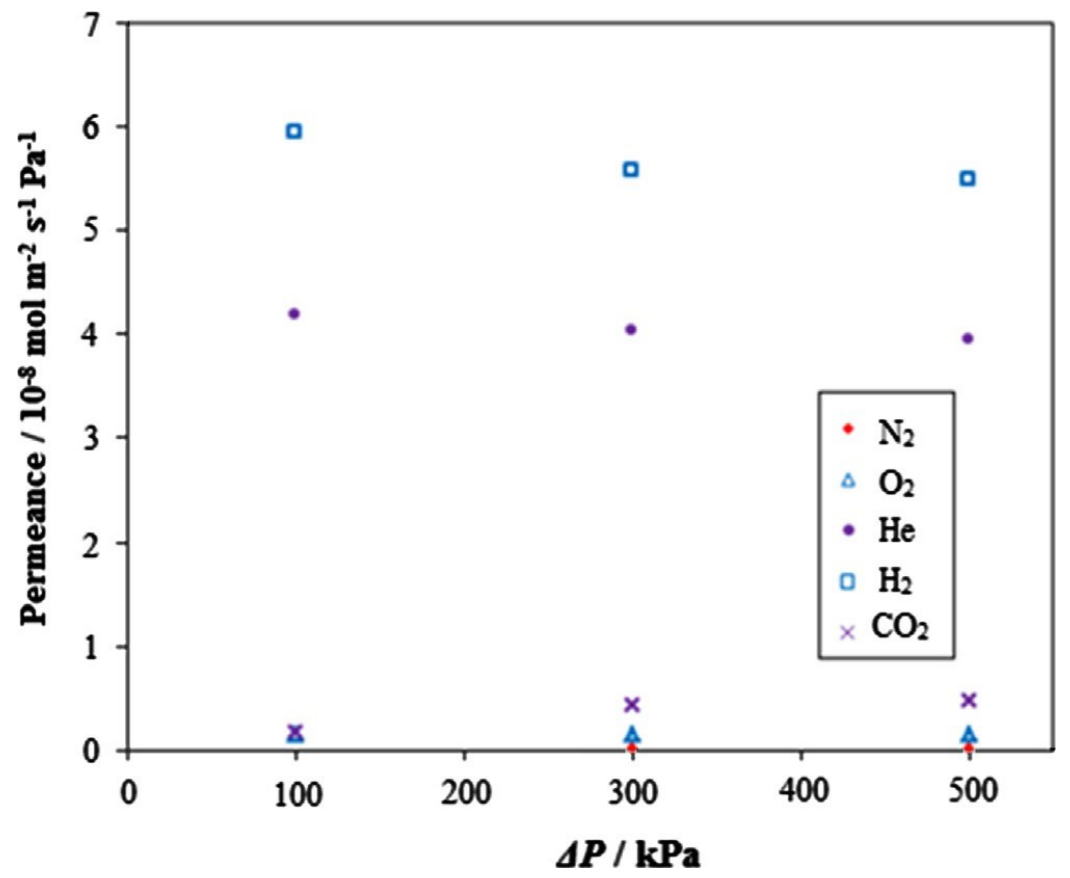

Fig. 12. Gases permeances as a function of feed pressure for CMSM 500. Mem- branes were activated at $140 \circ \mathrm{C}$ for $2 \mathrm{~h}$ under $\mathrm{N} 2$ atmosphere before permeation

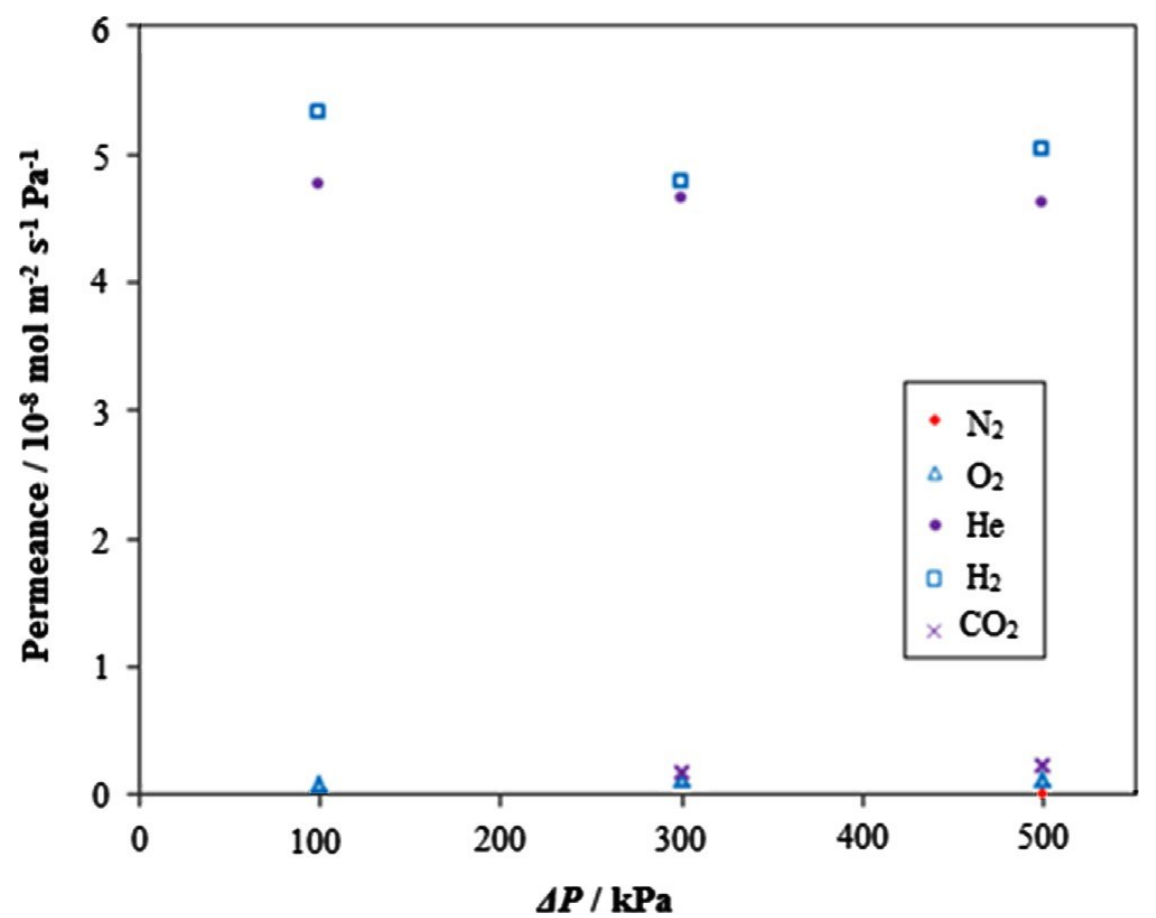

Fig. 13. Gases permeances as a function of feed pressure for CMSM 550. Mem- branes

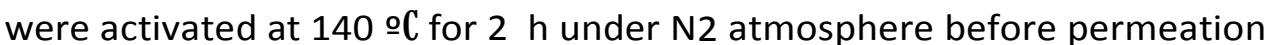



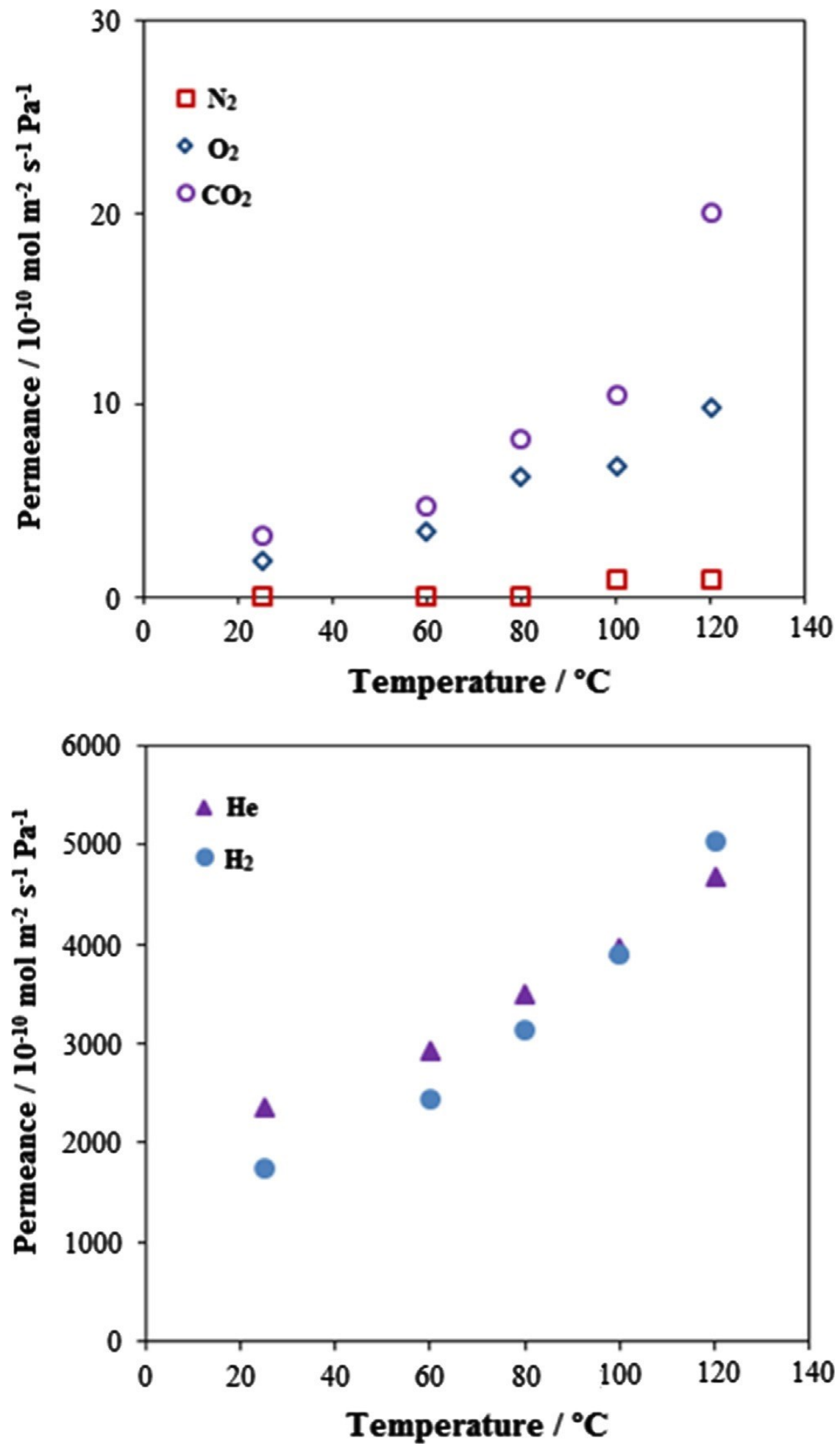

Fig. 14. Gases permeances as a function of temperature for CMSM 550. Membranes were activated at $140 \stackrel{\circ}{ } \mathrm{C}$ for $2 \mathrm{~h}$ under N2 atmosphere before permeation. 


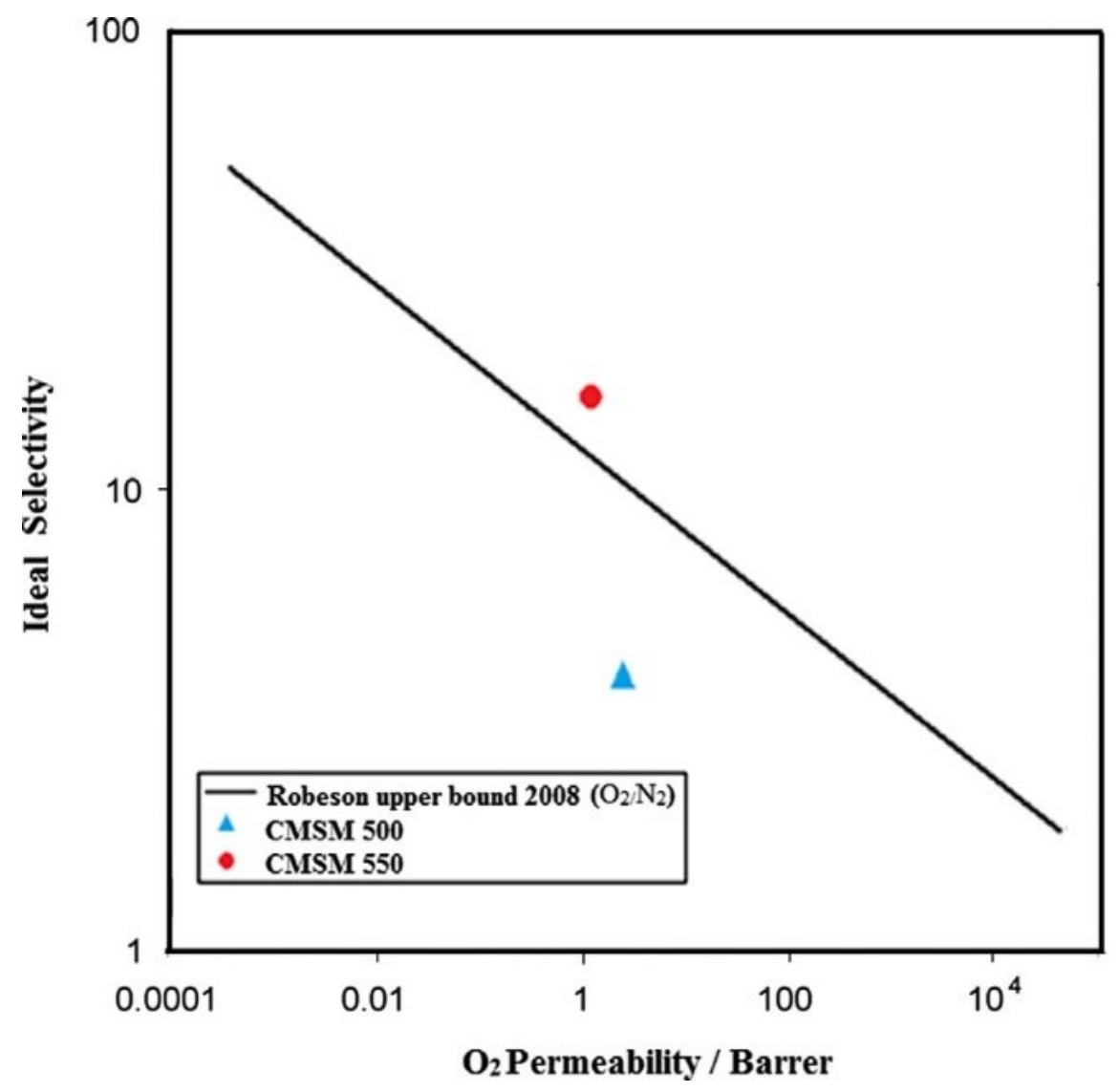

Fig. 15. Gas permeation results for O2/N2 in CMSM 500 and CMSM 550 and comparison with the respective upper bound plot.

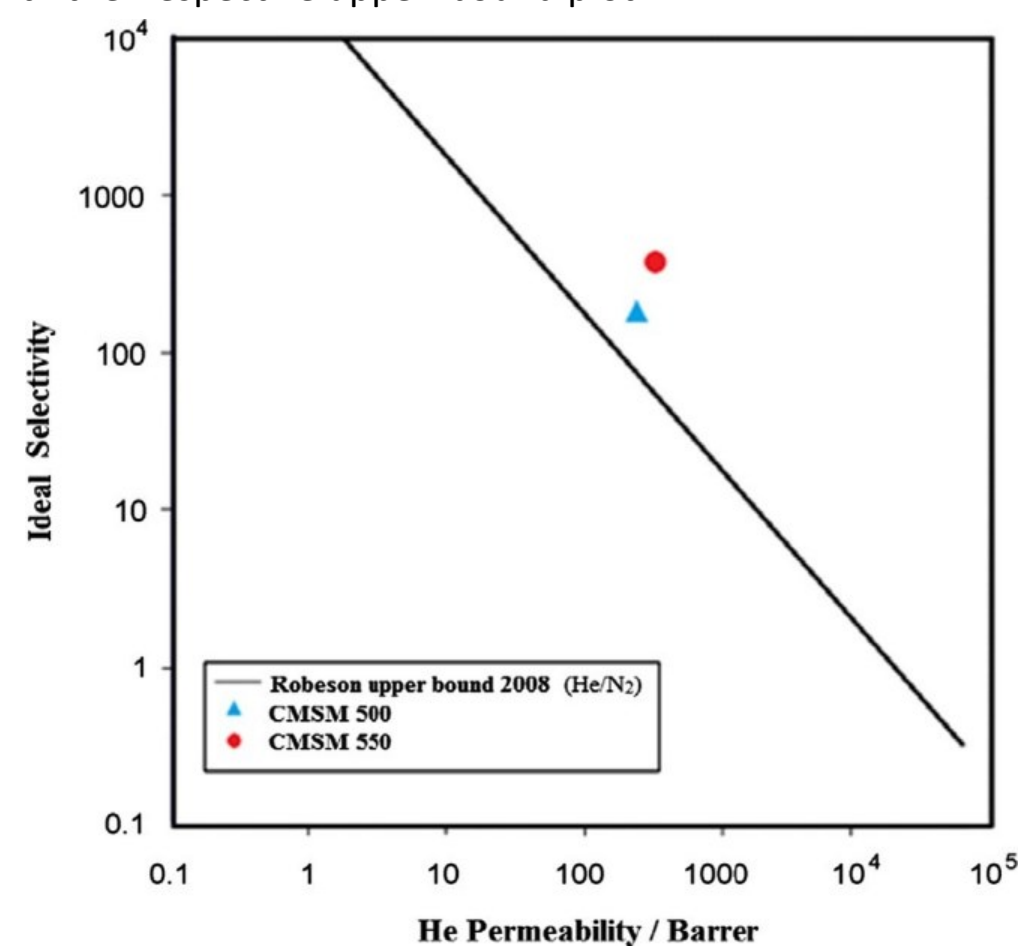

Fig. 16. Gas permeation results for He/N2 in CMSM 500 and CMSM 550 and comparison with the respective upper bound plot. 


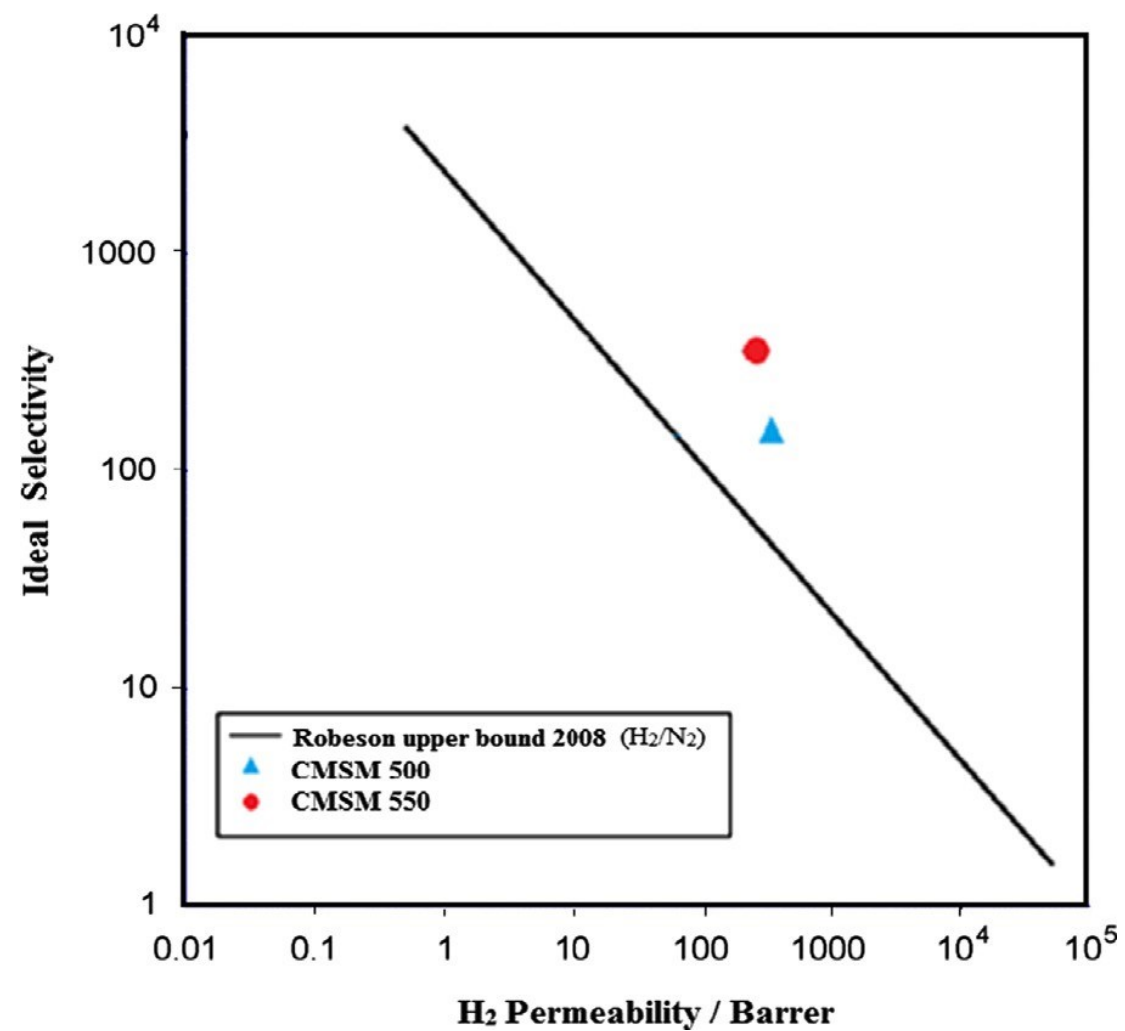

Fig. 17. Gas permeation results for $\mathrm{H} 2 / \mathrm{N} 2$ in CMSM 500 and CMSM 550 and comparison with the respective upper bound plot.

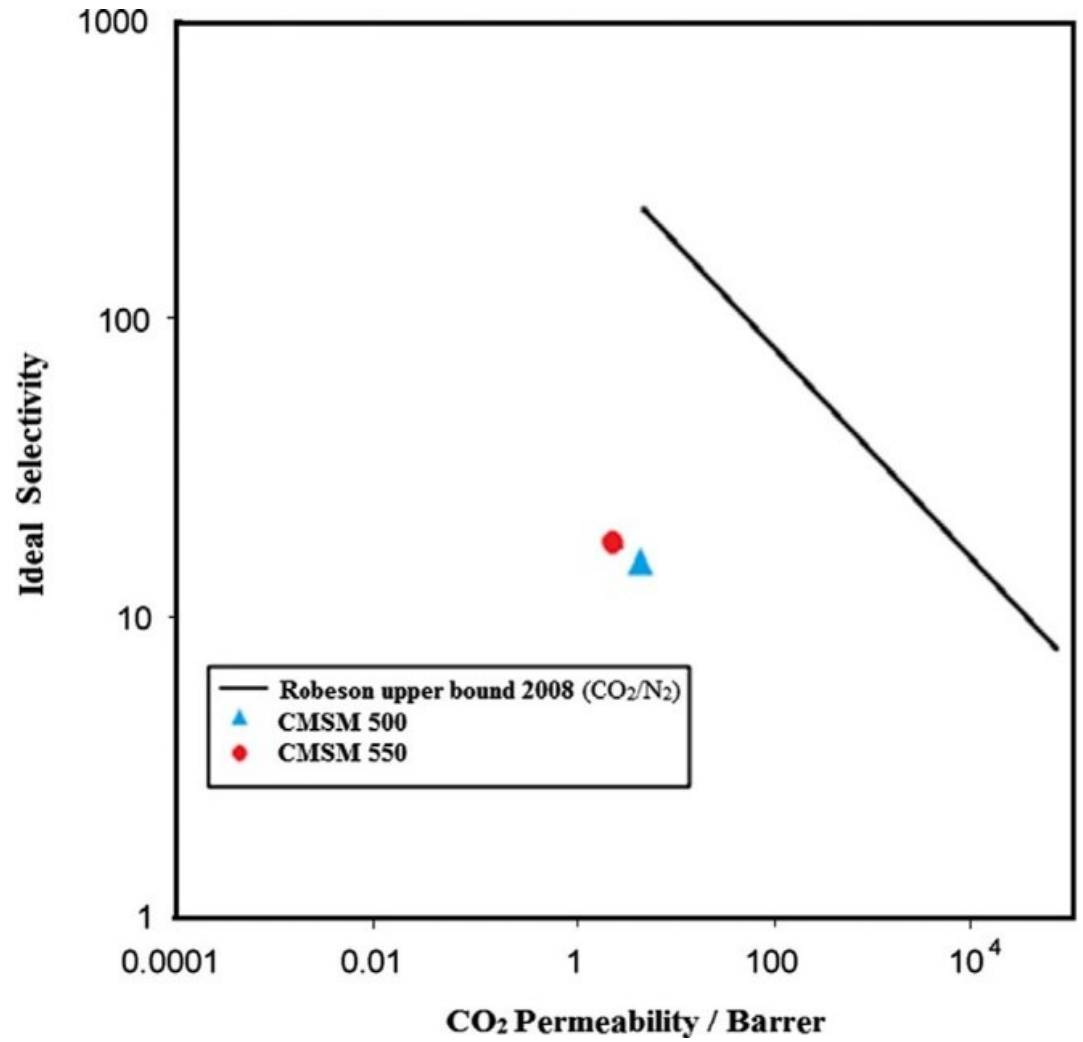

Fig. 18. Gas permeation results for CO2/N2 in CMSM 500 and CMSM 550 and comparison with the respective upper bound plot. 

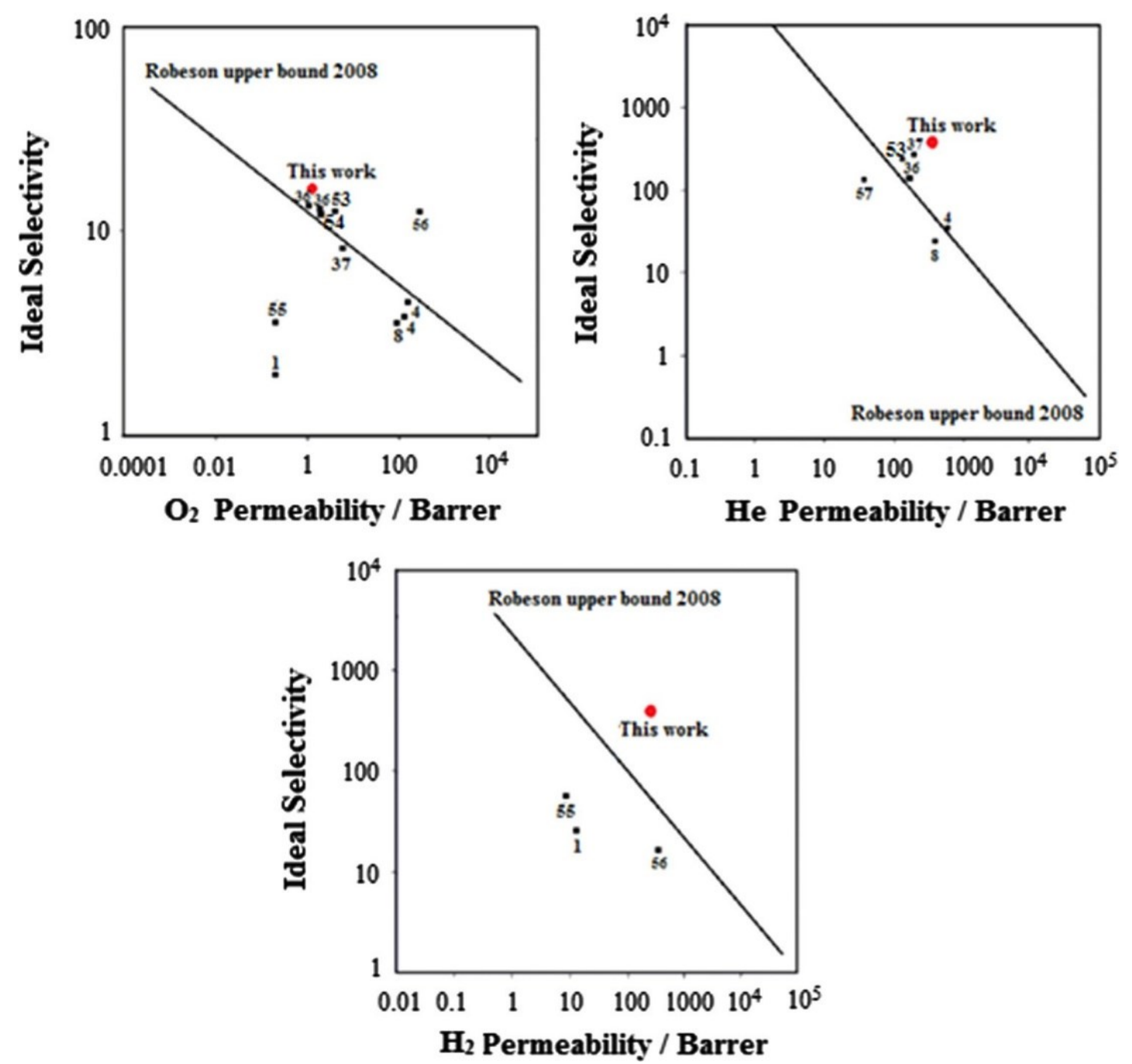

Fig. 19. Robeson upper limits and comparison with pure gas permeation results obtained with low cost phenol-formaldehyde resins derived carbon membranes. All selectivities are relative to $\mathrm{N} 2$. 
Table 1 Structural parameters for carbon molecular sieve membranes carbonized at 500 C and 550 으.

\begin{tabular}{lcc}
\hline Parameter & CMSM 500 & CMSM 550 \\
\hline$W_{0}\left(\mathrm{~cm}^{3} \mathrm{~g}^{-1}\right)$ & 0.13 & 0.40 \\
$E_{0}\left(\mathrm{~kJ} \mathrm{~mol}^{-1}\right)$ & 11.14 & 12.06 \\
$\ell(\mathrm{nm})$ & 0.68 & 0.58 \\
\hline
\end{tabular}

Table 2 Permeance properties as a function of the pressure difference for CMSM 500. Membranes were activated at 140 으 for $2 \mathrm{~h}$ under N2 atmosphere before permeation

\begin{tabular}{|c|c|c|c|c|c|}
\hline \multirow[t]{2}{*}{ Feed pressure $(\mathrm{kPa})$} & \multicolumn{5}{|c|}{ Permeance $\left(\mathrm{mol} \mathrm{m}^{-2} \mathrm{~s}^{-1} \mathrm{~Pa}^{-1}\right)$} \\
\hline & $\mathrm{N}_{2}$ & $\mathrm{O}_{2}$ & $\mathrm{He}$ & $\mathrm{H}_{2}$ & $\mathrm{CO}_{2}$ \\
\hline 500 & $2.465 \times 10^{-10}$ & $1.513 \times 10^{-9}$ & $3.947 \times 10^{-8}$ & $5.484 \times 10^{-8}$ & $4.831 \times 10^{-9}$ \\
\hline 300 & a & $1.562 \times 10^{-9}$ & $4.017 \times 10^{-8}$ & $5.571 \times 10^{-8}$ & $4.310 \times 10^{-9}$ \\
\hline 100 & a & $1.403 \times 10^{-9}$ & $4.189 \times 10^{-8}$ & $5.931 \times 10^{-8}$ & $1.615 \times 10^{-9}$ \\
\hline
\end{tabular}

${ }^{\text {a }}$ Below the detection limit.

Table 3 Permeance properties as a function of the pressure difference for CMSM 550. Membranes were activated at 140 으 for $2 \mathrm{~h}$ under N2 atmosphere before permeation.

\begin{tabular}{|c|c|c|c|c|c|}
\hline \multirow[t]{2}{*}{ Feed pressure $(\mathrm{kPa})$} & \multicolumn{5}{|c|}{ Permeance $\left(\mathrm{mol} \mathrm{m}^{-2} \mathrm{~s}^{-1} \mathrm{~Pa}^{-1}\right)$} \\
\hline & $\mathrm{N}_{2}$ & $\mathrm{O}_{2}$ & $\mathrm{He}$ & $\mathrm{H}_{2}$ & $\mathrm{CO}_{2}$ \\
\hline 500 & $<8.530 \times 10^{-11}$ & $1.062 \times 10^{-9}$ & $4.614 \times 10^{-8}$ & $5.029 \times 10^{-8}$ & $2.256 \times 10^{-9}$ \\
\hline 300 & a $0.000 \times 100$ & $1.075 \times 10^{-9}$ & $4.653 \times 10^{-8}$ & $4.775 \times 10^{-8}$ & $1.774 \times 10^{-9}$ \\
\hline 100 & a & $8.173 \times 10^{-10}$ & $4.766 \times 10^{-8}$ & $5.312 \times 10^{-8}$ & $<8.530 \times 10^{-10}$ \\
\hline
\end{tabular}

${ }^{\text {a }}$ Below detection limit. 
Table 4 Ideal selectivities for CMSM 500 and CMSM 550. Membranes were activated at 140 oC for 2 h under N2 atmosphere before experiments were performed.

\begin{tabular}{lrrrr}
\hline \multicolumn{5}{l}{ Ideal selectivity } \\
\cline { 2 - 5 } & $\mathrm{O}_{2} / \mathrm{N}_{2}$ & $\mathrm{He} / \mathrm{N}_{2}$ & $\mathrm{H}_{2} / \mathrm{N}_{2}$ & $\mathrm{CO}_{2} / \mathrm{N}_{2}$ \\
\hline CMSM500 & 5.9 & 221.0 & 158.0 & 15.4 \\
CMSM550 & $>11.5$ & $>544.0$ & $>586.0$ & $>23.3$ \\
\hline
\end{tabular}

